\title{
MEDIAL ANKLE PAIN AFTER LATERAL LIGAMENT RUPTURE
}

\author{
C. N. VAN DIJK, P. M. M. BOSSUYT, R. K. MARTI \\ From the University of Amsterdam, The Netherlands
}

\begin{abstract}
A fter a severe ankle sprain the incidence of residual complaints, particularly on the medial side of the joint, is high. We studied a consecutive series of $\mathbf{3 0}$ patients who had operative repair of acute ruptures of lateral ligaments. During operation, arthroscopy revealed a fresh injury to the articular cartilage in 20 ankles, in 19 at the tip and/or anterior distal part of the medial malleolus as well as on the opposite medial facet of the talus. In six patients, a loose piece of articular cartilage was found.

We conclude that in patients with a rupture of one or more of the lateral ankle ligaments after an inversion injury, an impingement occurs between the medial malleolus and the medial facet of the talus. Patients with a lesion of the lateral ankle ligament caused by a high-velocity injury (a faulty landing during jumping or running) had a higher incidence of macroscopic cartilage damage $(p<0.01)$, medially-located pressure pain $(p=0.06)$ and medially-located complaints at one-year follow-up $(\mathbf{p}=0.02)$ than those with a low-velocity injury (a stumble).
\end{abstract}

J Bone Joint Surg [Br] 1996;78-B:562-7.

Received 12 September 1995; Accepted after revision 9 February 1996)

After rupture of the lateral ankle ligaments symptoms frequently persist. Treatment is usually focused on the restoration of stability and most methods are successful (Kannus and Renström 1991). Despite this many patients have symptoms at short- and long-term follow-up. Residual complaints occur most frequently after plaster treatment for six weeks or more (Niethard 1974; Prins 1978; Moller-

C. N. van Dijk, MD, PhD

R. K. Marti, MD, PhD

Department of Orthopaedic Surgery

P. M. M. Bossuyt, MD, PhD

Department of Epidemiology

Akademisch Medisch Centrum, Meibergdreef 9, 1105 AZ Amsterdam, The Netherlands.

Correspondence should be sent to Dr C. N. van Dijk.

(C)1996 British Editorial Society of Bone and Joint Surgery 0301-620X/96/41229\$2.00
Larsen et al 1988).

The incidence of residual complaints is greater in athletes than in patients who undertake less strenuous activities (Van Beek 1985; Van der Ent 1985; Verhagen, de Keizer and van Dijk 1995), and apart from mechanical instability, these include functional instability, intermittent swelling, stiffness and pain (Freeman, Dean and Hanham 1965), which is the most frequent residual problem (Ruth 1961; Broström 1966; Staples 1972; Van der Ent 1985; Fischer and Schedl 1988). Its location is rarely specified, however, and most authors speak of 'a painful ankle'.

In our experience this pain is often on the medial side of the ankle, and a thorough physical examination of the joint shows tenderness on palpation of the anterior aspect of the medial malleolar region. We have tried to identify the cause of these medial problems, using arthroscopy to obtain a direct view of the medial side of the ankle. We report our findings in a consecutive series of patients who presented with acute rupture of the lateral ligaments of the ankle.

\section{PATIENTS AND METHODS}

The Accident and Emergency Department of the Academic Medical Centre in Amsterdam, a large teaching hospital, is freely accessible to patients without referral by a general practitioner. We studied a consecutive series of patients who presented within 48 hours of injury. All who complained of a painful ankle caused by indirect trauma were admitted to the study, but those with a history of previous ankle injury were excluded. There were 18 men and 12 women, with a mean age of 25.2 years (18 to 40 ); 17 right and 13 left ankles were involved. The mechanism of injury in 16 patients was turning the ankle while walking while 14 with more severe trauma had had a faulty landing while jumping or running.

Review of the databank of the Consumer Safety Institute showed that our patients had similar demographic data with regard to gender ratio, age, place of accident, patient activity at the time of accident and type of injury to all other patients admitted for ankle sprains to other Dutch hospitals during the same period.

All the patients had arthrography of the affected ankle within 48 hours and, for the purpose of this study, those with a positive arthrogram then had an operative repair of their lateral ligament rupture. The operation was performed on an outpatient basis when swelling had subsided at one 


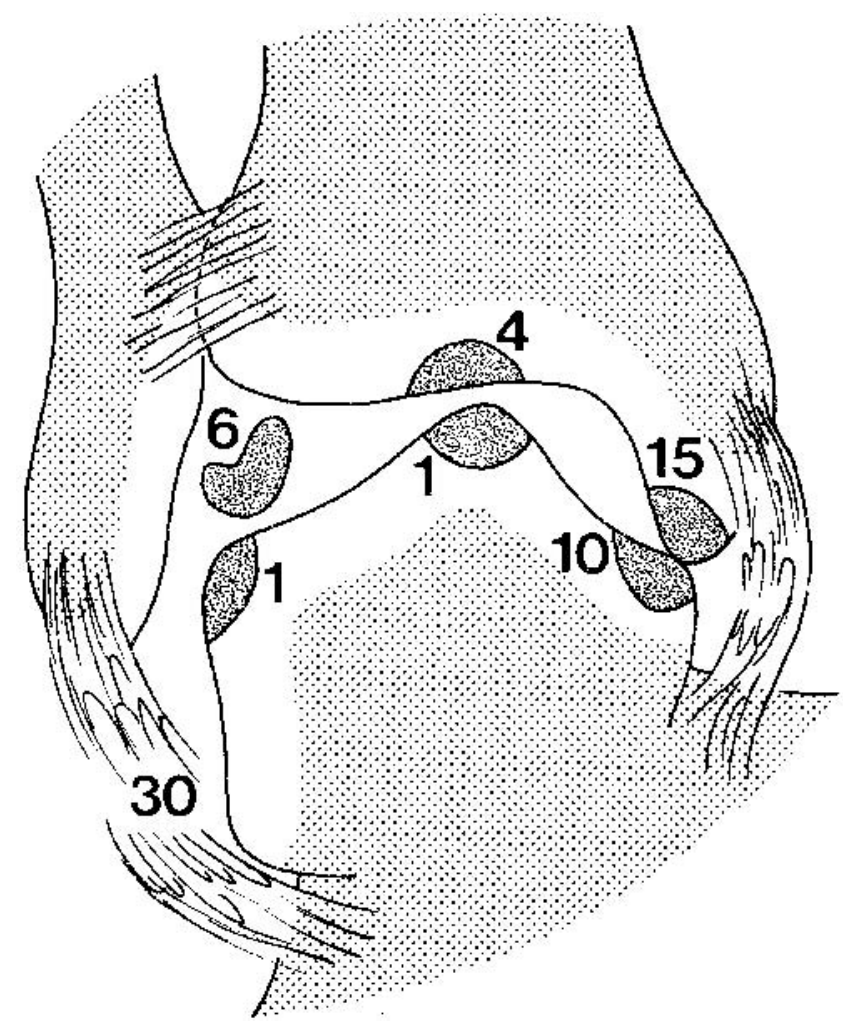

Fig. 1

The location and number of chondral and osteochondral lesions as found at arthroscopy in 30 consecutive patients with rupture of lateral ligaments of the ankle. There was only one lateral and one medial lesion of the talar dome, but 15 patients had damage at the tip or anterior edge of the medial malleolus. There were six loose cartilage fragments. with an inclination angle of $30^{\circ}$ introduced through the anterolateral capsule. The anterior and anteromedial compartments were assessed, with the joint in forced full dorsiflexion, and the talar dome inspected with the foot in plantar flexion and under manual distraction. All the lateral ligaments were viewed, as was the anterior tibiofibular or syndesmotic ligament. Chondral lesions were classified as follows: grade 0 , no lesion; grade 1, superficial lesion; grade 2, subchondral bone exposed; or grade 3, osteochondral or chondral defect with a loose body. Chondral and osteochondral lesions were left untreated.

After completion of the arthroscopy the ruptured ligaments were sutured and a plaster cast applied. After removal of the plaster at five days the functional after-treatment included firm bandaging for five weeks and full weightbearing. Review of the patients was at six months and one year after the initial injury. We used the chi-squared test to compare proportions between groups, and Fisher's exact test because of the small numbers.

\section{RESULTS}

Twenty patients had an isolated rupture of the anterior talofibular ligament and ten had multiple ligament ruptures. We found no lesions of the anterior tibiofibular ligament. The arthroscopic findings in the medial compartment were chondral lesions in 20 patients, traumatic synovitis in 19 , adhesions in nine and a partial rupture of the deltoid ligament in one. The typical locations of the chondral lesion were at the anterior edge or the tip of the medial malleolus, and the opposing medial facet of the talus (Figs

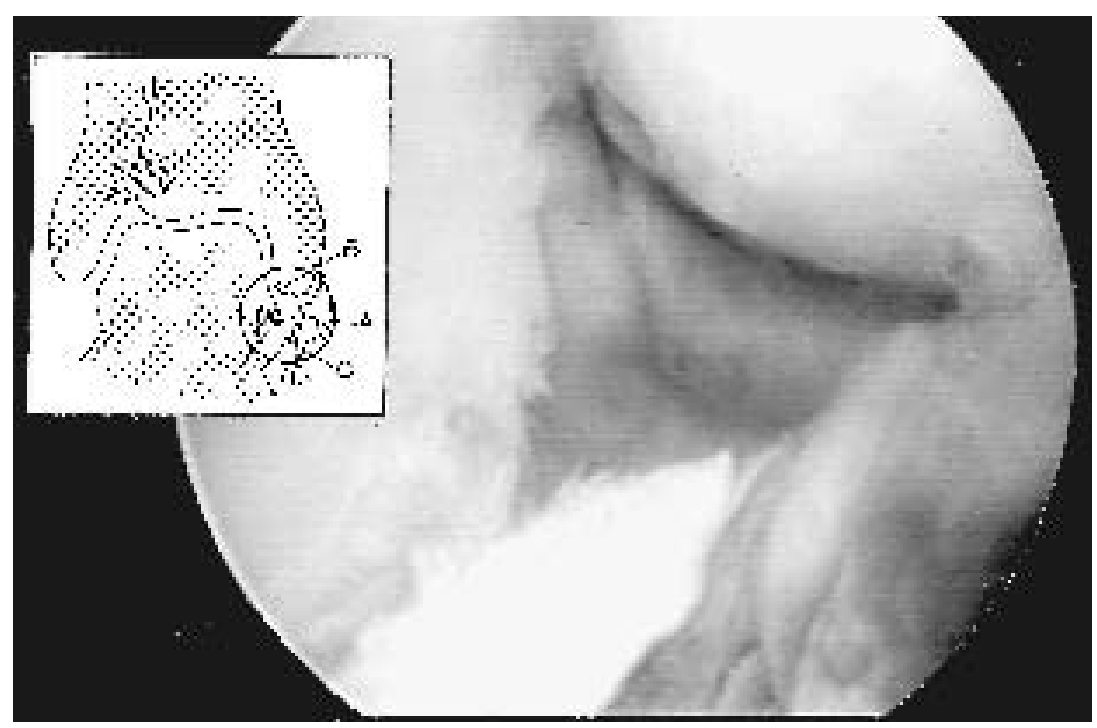

Fig. 2

A 21-year-old man twisted his right ankle during trampoline jumping, rupturing his anterior talofibular ligament. The arthroscopic view shows traumatic synovitis (A), a small round defect on the tip of the medial malleolus (B), and a chondral flake fracture of the medial facet of the talus (C). The chondral flake fragment was irrigated out of the joint. There were no complaints at six months or at one year.

week, on average, after injury. The ankles were re-examined before operation by the first author (CND) and the procedure was as described in detail by Prins (1978).

We performed arthroscopic examination of the whole ankle during the operation, using a $4 \mathrm{~mm}$ arthroscope
1 to 6). In six patients a loose cartilage fragment was found and removed. There were no postoperative complications.

At the six-month follow-up none of the patients expressed a fear of giving way or any other symptoms of secondary instability. After one year, 7 of the 19 patients 


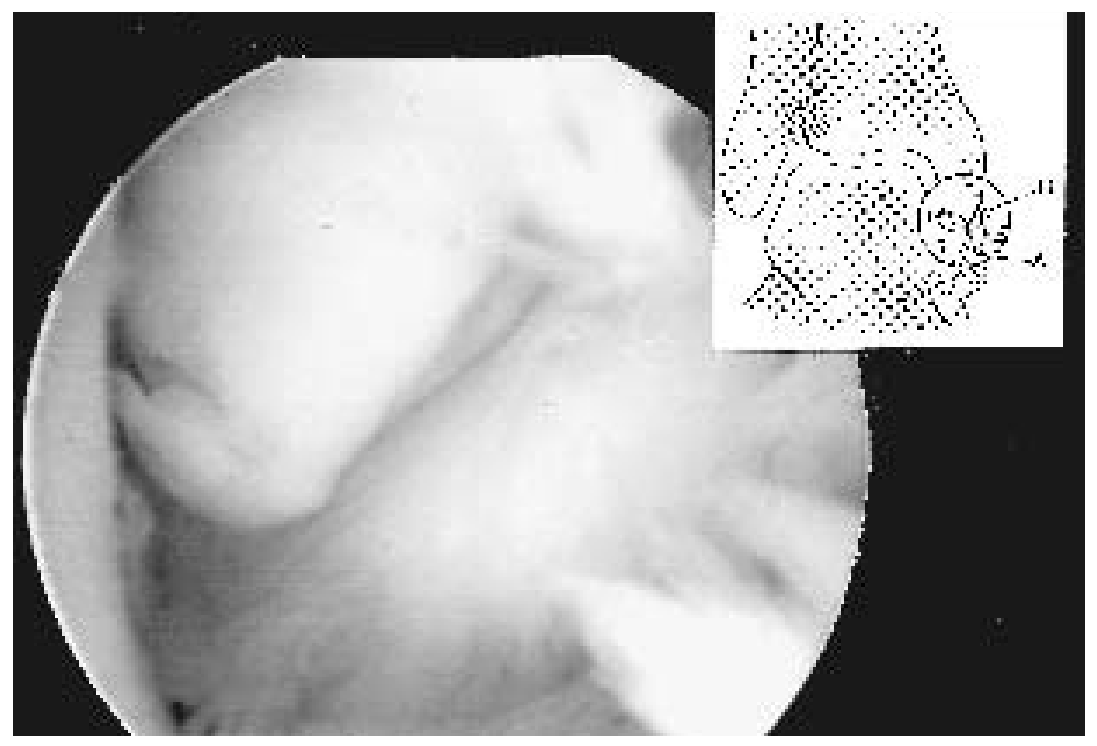

Fig. 3

A 22-year-old man twisted his right ankle after jumping at football, sustaining rupture of his anterior talofibular ligament and a partial lesion of the calcaneofibular ligament (CFL). The arthroscopic view shows synovitis (A) and a chondral flake fracture of the tip of the medial malleolus (B). The fragment was left in place. At six months and one year there was local tenderness, but no complaints.

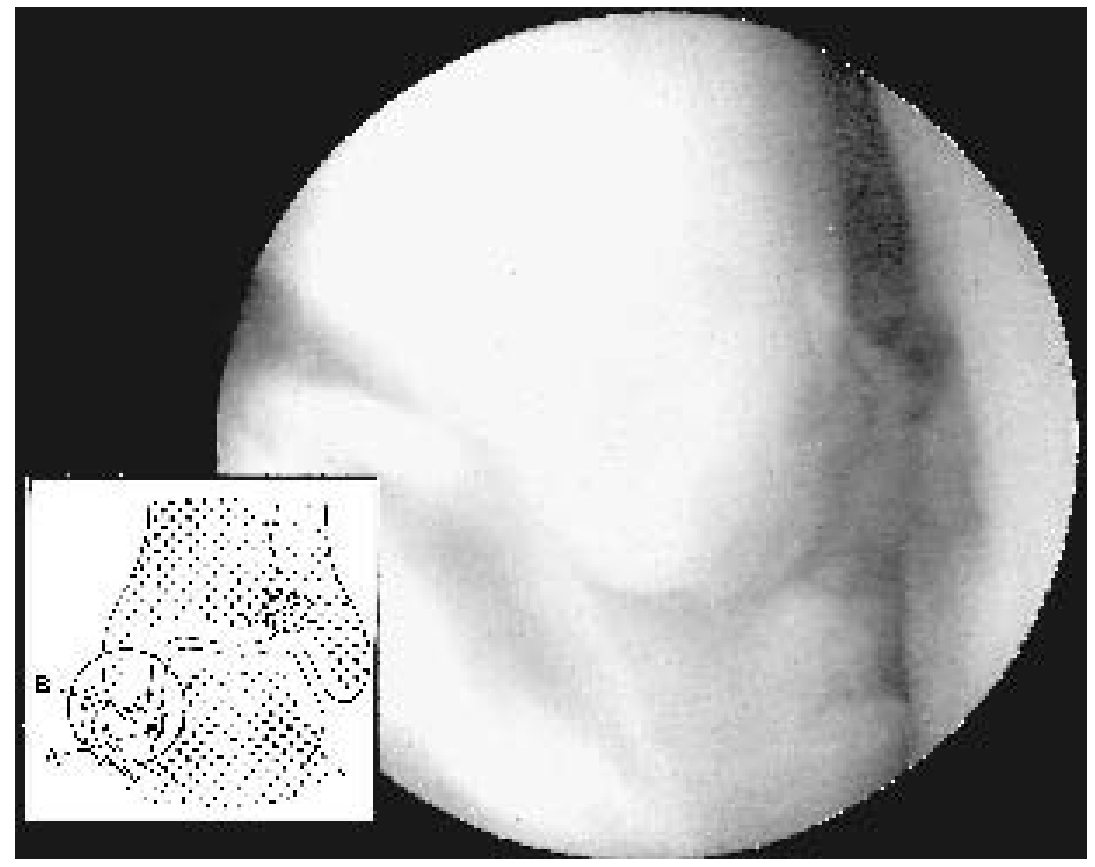

Fig. 4

A 27-year-old woman twisted her ankle by landing on an opponent's foot while playing volleyball. At operation after a positive arthrogram, a partial rupture of the anterior talofibular ligament was found. The arthroscopic view shows an impression defect on the medial facet of the talus (A) and an irregular tip of the medial malleolus (B). At six months and one year she had residual complaints which made sporting activities impossible. Arthroscopic debridement and reduction of the tip of the medial malleolus at 14 months after the original trauma, cured the complaints and allowed full return to competitive volleyball after four months.

with medial chondral lesions had pain on this side of the joint but none of the 11 without such damage had complaints at this site. This difference is statistically highly significant $(\mathrm{p}<0.001)$. The medial complaints hindered daily activities in five patients, and caused pain and some swelling after sport in the other two. None of these patients

Table I. The results of examination at five days (5D) six months $(6 \mathrm{M})$ and one year (1Y) after the original injury and the patients' complaints at one year, both related to the mechanism of trauma and the extent of the lateral ligament lesion

\begin{tabular}{|c|c|c|c|c|c|c|c|c|c|c|}
\hline & \multicolumn{6}{|c|}{ Tenderness } & \multicolumn{4}{|c|}{ Complaints at one year } \\
\hline & \multicolumn{3}{|c|}{ Medial } & \multicolumn{2}{|c|}{ Lateral } & \multirow[b]{2}{*}{$1 Y$} & \multicolumn{2}{|c|}{ Medial } & \multicolumn{2}{|c|}{ Lateral } \\
\hline & 5D & $6 \mathrm{M}$ & $1 Y$ & 5D & $6 M$ & & Pain & Stiffness & Pain & Stiffness \\
\hline \multicolumn{11}{|l|}{ Injury mechanism } \\
\hline Walking $(\mathrm{n}=16)$ & 13 & 2 & 2 & 16 & 5 & 2 & 1 & 1 & 1 & 0 \\
\hline Jumping or running $(\mathrm{n}=14)$ & 13 & 11 & 9 & 14 & 2 & 1 & 6 & 2 & 1 & 0 \\
\hline \multicolumn{11}{|l|}{ Ligament lesion } \\
\hline Single $(\mathrm{n}=20)$ & 17 & 8 & 6 & 20 & 6 & 2 & 4 & 2 & 1 & 0 \\
\hline Multiple $(\mathrm{n}=10)$ & 9 & 5 & 5 & 10 & 1 & 1 & 3 & 1 & 1 & 0 \\
\hline
\end{tabular}




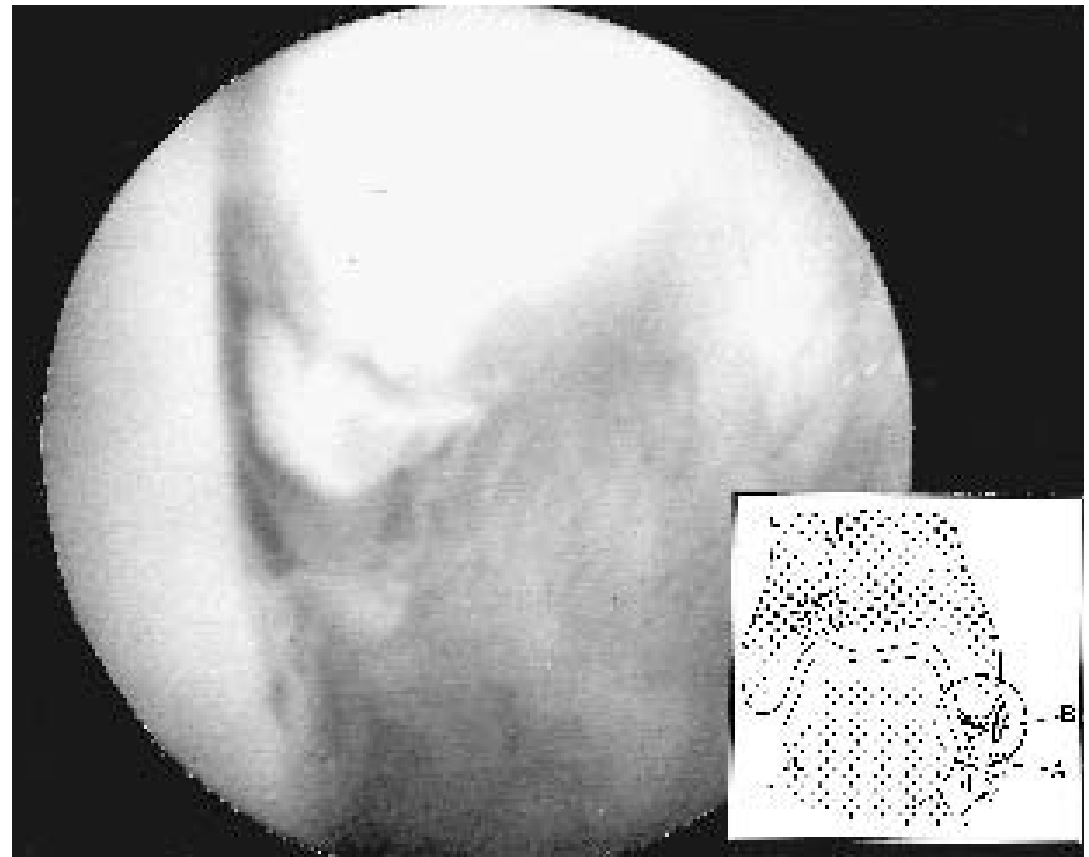

Fig. 5

A 26-year-old professional female ballet dancer made a faulty landing on stage, sustaining anterior talofibular, calcaneofibular and partial posterior talofibular ligament lesions. The arthroscopic view shows a single adhesion (A) and a chondral flake fracture at the tip of the medial malleolus (B). The fragment was left in place, and at six months she still had some pain during performances. At one year she had only stiffness after performances with pain only after very strenuous activity.

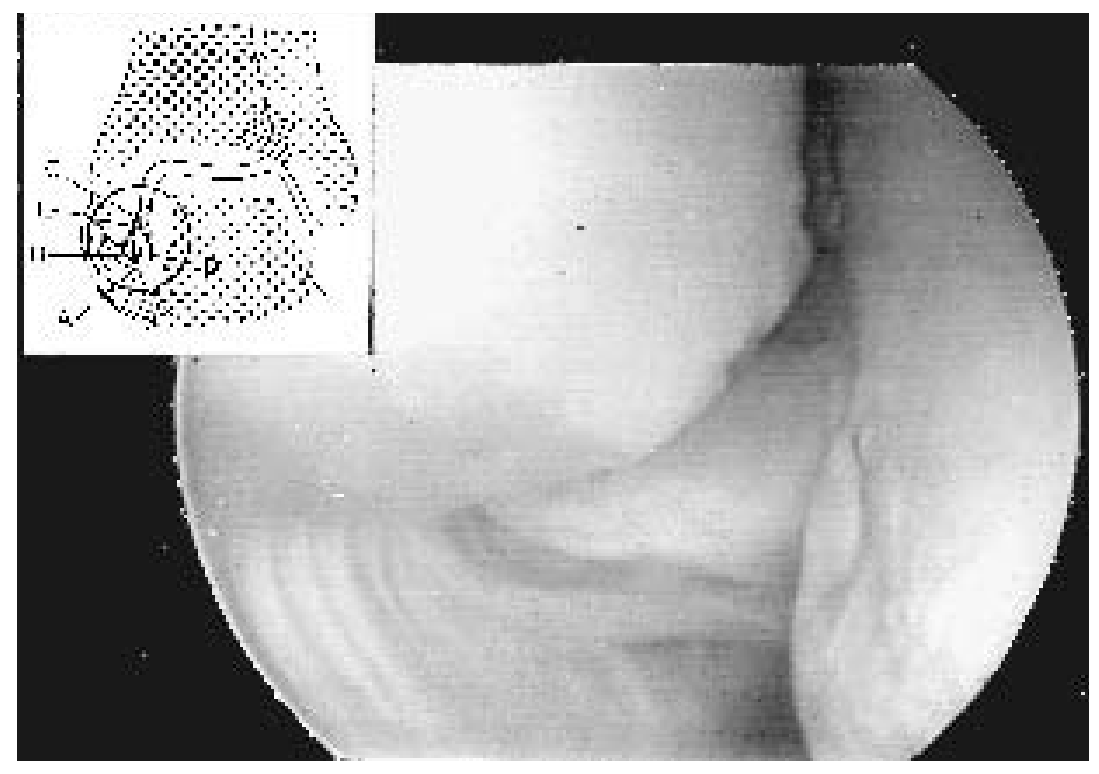

Fig. 6

A 39-year-old female korfball player made a faulty landing after a jump sustaining rupture of her anterior talofibular ligament. The arthroscopic view shows the separate bundles of the deltoid ligament (A-C), a small cartilage flake fracture (D) and some irregularity of the tip of the medial malleolus (E). At six months and one year she had residual complaints during daily activities and sport was impossible. Arthroscopic debridement and reduction of the tip of the medial malleolus at 14 months after the original trauma relieved the complaints and allowed full return to competitive korfball after three months.

Table II. Mechanism of injury related to the extent of the lateral ligament lesion and the extent of chondral damage on the medial side

\begin{tabular}{|c|c|c|c|c|c|c|}
\hline & \multicolumn{2}{|c|}{ Ligament lesion } & \multirow{2}{*}{\multicolumn{4}{|c|}{ Medial chondral lesion grading }} \\
\hline & \multirow{2}{*}{$\begin{array}{l}\begin{array}{l}\text { Single } \\
(\mathbf{n}=20)\end{array} \\
\end{array}$} & \multirow{2}{*}{$\begin{array}{l}\text { Multiple } \\
(\mathbf{n}=10)\end{array}$} & & & & \\
\hline & & & $\mathbf{0}$ & $\mathbf{I}$ & II & III \\
\hline Walking $(\mathrm{n}=16)$ & 13 & 3 & 9 & 4 & 2 & 1 \\
\hline Jumping or running $(\mathrm{n}=14)$ & 7 & 7 & 1 & 0 & 6 & 7 \\
\hline
\end{tabular}

feared giving way or had symptoms of secondary instability.

The patients who were symptom-free and those with medial complaints were comparable in age, gender ratio, severity of the initial symptoms and the amount of initial swelling. The 14 patients injured while jumping or running had significantly more medial tenderness at one year $(\mathrm{p}<0.01$; Table I) and more frequent medial complaints 
$(\mathrm{p}=0.02)$ than those who sustained low-velocity trauma. We found no statistical difference between the two groups for tenderness or complaints on the lateral side of the joint.

There were no statistical differences in tenderness or complaints between patients with rupture of a single ligament and those with multiple ligament lesions (Table II). The patients with more severe trauma had relatively more multiple ligament lesions, but the difference was not statistically significant $(\mathrm{p}=0.12)$. There was, however, a statistically significant difference in the incidence of medial cartilage injury $(\mathrm{p}<0.001)$ between patients with mild as opposed to more severe mechanisms of trauma.

\section{DISCUSSION}

Problems with the medial side of the ankle in association with acute lateral ligament injuries have been described. Partial rupture of the deltoid ligament is mentioned by Kaufmann (1922), Goldstein (1948), Heim (1978) and Rasmussen and Kromann-Andersen (1983), but in our series, only one patient had such a rupture. Other described causes are capsular lesions (Huebner 1965), haemarthrosis (Hackenbruch and Karpf 1977), fracture of the medial malleolus (Hem 1978, 1981) and traumatic synovitis (Martin, Curl and Baker 1989). Only one patient in our series with partial rupture of the deltoid ligament showed any medial leakage of contrast on arthrographic examination. Medial malleolar fracture was ruled out by negative radiographs in all our patients. We found traumatic synovitis at one week in 19 of our 30 patients, and this was the only abnormal medial finding in six of these, none of whom had any symptoms at the six-month and one-year follow-up.

Twenty of our patients had a macroscopic chondral lesion. Osteochondral and chondral lesions are known to occur after supination trauma; the reported frequency varies from $0 \%$ to $7 \%$ (Bosien, Staples and Russell 1955; Lippert, Hawe and Bernett 1989), but the typical location which has been described is at the dome of the talus anterolaterally or posteromedially (Berndt and Harty 1959; Biedert 1989). In our series two patients had such a lesion, one anterolateral and one posteromedial.

Our finding of collision between the medial malleolus and the talus has been previously described (Kleiger 1956) and compression fractures on the medial side of the foot after inversion trauma have been reported by van der Werken and Marti (1982). Changes in cartilage, bony spurs, chronic synovitis and scar tissue are recognised as the main causes of chronic pain in the medial ankle by arthroscopic surgeons (Biedert 1989; Lundeen 1990; van Dijk 1990), and it seems likely that these result from the injuries to articular cartilage which we have shown to be caused by initial trauma in supination.

The energy transfer at the time of a severe inversion sprain is a traction force on the lateral side with a compression force medially. When there is rupture of the lateral ligaments, the talus is rotated out of the ankle mortice, and in this subluxated, supinated position the body-weight causes axial compression through the medial malleolus and the medial talar facet (see Fig. 1). These shearing and impaction forces easily explain the cartilage damage. More severe trauma produces more multiple ligament lesions and more extensive cartilage damage.

We have shown that patients with more extensive cartilage damage had a higher incidence of residual complaints, and this difference would have been even greater if the three patients who had removal of a loose cartilage fragment and were symptom-free at one year had been added to the symptomatic group. Long-term cartilage damage may lead to degenerative changes, and this is especially true if there is continued or recurrent instability; every sprain has the potential to add new damage. Harrington (1979) reported 34 cases of osteoarthritis of the ankle in patients with chronic ligament instability; in all 34 the degenerative changes were on the medial side of the joint, between the medial malleolus and the talus. Most of the lesions seen in our study did not involve weight-bearing surfaces, and are unlikely to lead to progressive arthritic changes. The cartilage damage, however, can be expected to cause a repair reaction with soft-tissue scarring, ossification and spur formation. Such spurs are then not due to osteoarthritis, but are the result of local damage outside the weight-bearing surface.

Ten of our 30 patients had residual complaints at one year. All had stable ankles, but four of them had complaints severe enough for us to offer surgery. Three had arthroscopic surgery for debridement of the damaged region (Figs 4 and 6), at 14 to 16 months after the original injury. All three were symptom-free within three months and were able to make a full return to competitive sport. The fourth patient refused surgery and stopped his sporting activities.

No benefits in any form have been received or will be received from a commercial party related directly or indirectly to the subject of this article.

\section{REFERENCES}

Berndt AL, Harty M. Transchondral fractures (osteochondritis dissecans) of the talus. J Bone Joint Surg [Am] 1959;41-A:988-1020.

Biedert R. Osteochondral lesions of the talus. Unfallchirurg 1989;92: 199-205.

Bosien WR, Staples OS, Russell SW. Residual disability following acute ankle sprains. J Bone Joint Surg [Am] 1955;37-A:1237-43.

Broström L. Sprained ankles. V. Treatment and prognosis in recent ligament ruptures. Acta Chir Scand 1966;132:537-50.

Freeman MAR, Dean MRE, Hanham IWF. The etiology and prevention of functional instability of the foot. J Bone Joint Surg [Br] 1965; 47-B:678-85.

Goldstein LA. Tear of the lateral ligament of the ankle. New York State J Medicine 1948;48:199-201.

Hackenbruch W, Karpf PM. Injuries of the capsular ligament of the ankle joint. Fortschr Med 1977;95:1599-605.

Harrington KD. Degenerative arthritis of the ankle secondary to longstanding lateral ligament instability. J Bone Joint Surg [Äm] 1979; 61-A:354-61.

Heim U. Die verletzungen des medialen Bandapparates am oberen Sprunggelenk und ihre Behandlung. In: Burri C, Rüter A, eds. Verletzungen Des Oberen Sprunggelenkes. Berlin: Springer-Verlag, 1978:125-36.

THE JOURNAL OF BONE AND JOINT SURGERY 
Heim U. Pathologie, Klinik und Differentialdiagnose der Bandrisse an den Sprunggelenke. Z Unfallchir Versicherungsmed Berufs 1981;74:39-53.

Huebner L. Uber verletzungen am unteren ende des schienbeines. Hefte Unfallheilkunde 1965;81:125-6.

Jaskulka R, Fischer G, Schedl R. Injuries of the lateral ligaments of the ankle joint: operative treatment and long term results. Arch Orthop Trauma Surg 1988;107,4:217-21.

Kannus P, Renström P. Treatment for acute tears of the lateral ligaments of the ankle. J Bone Joint Surg [Am] 1991;73-A:305-12.

Kaufmann C. Die verstauchung der grossen Extremitätengelenke. Schweiz Med Wschr 1922;52:737-46.

Kleiger B. The mechanism of ankle injuries. J Bone Joint Surg [Am] 1956;38-A:59-70.

Lippert MJ, Hawe W, Bernett P. Surgical therapy of fibular capsuleligament rupture. Sportverletz Sportschaden 1989;3,1:6-13.

Lundeen RO. Ankle arthroscopy in the adolescent patient. J Foot Surg 1990;29:510-5.

Martin DF, Curl WW, Baker CL. Arthroscopic treatment of chronic synovitis of the ankle. Arthroscopy 1989;5:110-4.

Moller-Larsen F, Wethelund JO, Jurik AG, de Carvalho A, Lucht U. Comparison of three different treatments for ruptured lateral ankle ligaments. Acta Orthop Scand 1988;59:564-6.
Niethard FU. The mechanical stability of the ankle joint after rupture of the lateral ligament. Arch Orthop Unfallchir 1974;80:53-61.

Prins JG. Diagnosis and treatment of injury to the lateral ligament of the ankle: a comparative clinical study. Acta Chir Scand 1978; Suppl 486 : 3-149.

Rasmussen O, Kromann-Andersen C. Experimental ankle injuries: analysis of the traumatology of the ankle ligaments. Acta Orthop Scand 1983;54:356-62.

Ruth CJ. The surgical treatment of injuries of the fibular collateral ligaments of the ankle. J Bone Joint Surg [Am] 1961;43-A:229-39.

Staples OS. Result study of ruptures of lateral ligaments of the ankle. Clin Orthop 1972;85:50-8.

Van Beek P. Evaluation of ankle injuries using the Cybex II dynamometer. Acta Orthop Scand 1985;56:516.

Van Der Ent FW. Results of primary operative treatment of lateral ankle ligament lesions. Acta Orthop Scand 1985;56:513-4.

Verhagen RA, de Keizer G, van Dijk CN. Long-term follow-up of inversion trauma of the ankle. Arch Orthop Trauma Surg 1995;114:92-6.

Werken van der Chr, Marti RK. Gelukkig is uw enkel niet gebroken, hooguit verstuikt. Ned Tijdschr Gen 1982;126,47:2129-32. 